\title{
Recordando los hitos del pensamiento latinoamericano*
}

\author{
Julián González Zúñiga \\ Instituto de Estudios Latinoamericanos \\ Universidad Nacional, Costa Rica
}

1 1 pensamiento de América Latina, a diferencia del pensamiento europeo, no suele ser el resultado de elucubraciones surgidas del quehacer filosófico. No obstante la influencia que pueda encontrarse de algunas corrientes del pensamiento occidental en boga, se trata sobre todo de una reflexión nacida a la luz y en medio de la práctica social. Sus precursores han sido hombres y mujeres inmersos en la realidad y es a partir de ésta que han creado un pensamiento o un ideario en diferentes momentos y espacios. Cinco suramericanos en el s. XIX y la primera mitad del siglo XX han escrito obras hoy consideradas como ejemplos de una propuesta que pudo tener una influencia importante en su tiempo y que todavía guardan relación con el presente latinoamericano. Los textos del venezolano Simón Bolívar, el argentino Domingo Faustino Sarmiento, el cubano José Martí, el uruguayo José Enrique Rodó y el peruano José Carlos Mariátegui se constituyen, por lo tanto, en pilares del pensamiento latinoamericano $\mathrm{y}$ en hitos que marcan puntos de partida para el estudio de nuestra realidad.

\section{Carta de Jamaica de Simón Bolívar}

El texto de Bolívar dentro de su tono epistolar reúne características propias de un ensayo por tratarse de una exposición orgánica de ideas, con una base ideológica y algunos rasgos de literaturidad. Más argumentativo que persuasivo, se trata de un discurso de interpretación de la realidad en el contexto político de la época (1815).

Bolívar, como sujeto creador identificado, asume la autoría desde una primera persona plural y utiliza palabras textuales de la misiva de su interlocutor jamaiquino a quien dirige esta carta-respuesta. Estas mismas citas generan la exposición de ideas de parte de Bolívar en la medida en que va respondiendo a las inquietudes de su destinatario, creando así un diálogo imaginario que le confiere vivacidad al texto.

No obstante el cuidado y precisión en el uso del lenguaje, no prevalece el recurso

* Apuntes del conversatorio con estudiantes de la Licenciatura en Estudios Latinoamericanos del IDELA, 1995. 
a las figuras retóricas, las cuales son sustituidas por imágenes de lo concreto para ilustrar mejor. Este aspecto marca una notable diferencia con el ensayo de Martí "Nuestra América", los que podríamos calificar respectivamente como la voz del político visionario y la voz del poeta visionario. En cambio, con los dos casos se hace patente la profunda erudición de los autores, aunque el ensayo de Bolívar hace gala de un gran conocimiento de la realidad y de la historia del mundo, así como de la problemática de cada país de América, mientras que el texto de Martí tiende a circunscribirse a la realidad local.

Parte del estilo argumentativo de Bolívar son las comparaciones de hechos del pasado y del presente, de otras latitudes con nuestro continente, de personajes de allá, modalidad que refuerza la función didáctica del texto al presentar en blanco y negro los ejemplos más ilustrativos y los casos más elocuentes.

Bolívar se aferra a una línea temática central que mantiene de principio a fin: la oposición España-América, la primera como la gran opresora y la segunda como la desvalida víctima de esa opresión. De aquí en adelante va matizando, con una fuerte carga negativa hacia España, con fuertes calificativos y referencias que la descalifican:

- las barbaridades que los españoles cometieron

- desnaturalizada madrastra

- $\quad$ raza de exterminadores

- $\quad$ vieja serpiente
- $\quad$ usurpadores españoles

- $\quad$ esa nación avarienta

En la misma relación binaria se manifiestan los dos conceptos abstractos que son la columna vertebral del texto: libertad/ opresión, los cuales producen a su vez los otros elementos:

- libertad: trabajar la tierra, ocupar cargos de dignidad y jerarquía, derechos;

- opresión: siervos para el trabajo, simples consumidores, prohibiciones, privarnos de los derechos.

Con el párrafo que se inicia con la frase "Yo deseo más que otro alguno ver formar en América...", el ensayo marca una segunda fase: la esperanza de un nuevo despertar, y para ello Bolívar explica cuál es ese camino y cuáles obstáculos pueden presentarse por causa de las mismas debilidades de las naciones americanas. Al final señala la unión como la salida posible sobre la base del esfuerzo común y no por designio divino. En este punto el texto de Bolívar establece una exhortación al trabajo conjunto por un destino común: una comunidad de naciones libres de la opresión española.

\section{Introducción a "Facundo" de Domingo F. Sarmiento}

Domingo Faustino Sarmiento (18111888) escribe Civilización y barbarie. Vida de Juan Facundo Quiroga, publicado en Chile en mayo y junio de 1845 durante su exilio en este país, en el periódico $E l$ progreso. La obra, conocida simplemente como Facundo, es un acucioso diagnóstico 
sobre la dictadura y sus causas. El autor atribuye la crisis política a la oposición entre civilización y barbarie; la primera representada por la cultura europea que se conoce solamente en las grandes ciudades como Buenos Aires; la segunda representada por la pampa en el vasto desierto argentino. La solución a la crisis nacional es llevar la civilización, o cultura europea no española, a todo el territorio para así evitar el caudillismo que estaba echando raíces. Esta tesis política planteada desde la "Introducción" toma mayor fuerza en el relato, sustentada en tres partes:

- $\quad$ estudio de la pampa y del gaucho; división política y relación de clases sociales;

- biografía de Juan Facundo Quiroga, caudillo gaucho cercano al dictador Juan Manuel Rosas quien lo traiciona matándolo;

- ataque político contra el gobernante Rosas y compendio de las ideas de Sarmiento para construir la nación que él sueña para los argentinos.

Por lo anterior, Facundo es una obra de difícil ubicación. Es a la vez ensayo, programa político, relato con rasgos literarios cercano al género narrativo (incluye personajes y acontecimientos con matices de ficción), historia, tratado sociológico, testimonio y biografía. La "Introducción" a la obra es a la vez un texto que cobra vida propia como ensayo, por varias razones:

- tono exhortativo para inducir a la lectura de Facundo y dar a conocer lo que pasa en Argentina;
- carácter interpretativo que permite inferir el pensamiento político y social de Sarmiento, quien fue educador y político; combatió a Rosas con el arma de las ideas;

- literaturidad, establecida a partir de un estilo sincero con base en una fuerte construcción de frases largas que aluden constantemente al lector, así como el uso de imágenes que impactan, muy directas y sin retoricismos;

- marcada erudición, propia de un escritor con aires enciclopedistas, pero sobre todo con un gran manejo de temas atinentes a su realidad, a la vez que cosmopolita y conocedor de los clásicos;

- planteamiento de ideas que conforman un programa político y un ideario propio para Argentina y, por extensión, para América Latina. De aquí se desprende su amor por la cultura europea no hispana y su afinidad hacia los Estados Unidos, vistos como modelos dignos de ser imitados, cuya influencia es cada vez más necesaria para vencer la crisis nacional;

- $\quad$ subjetividad, que se palpa en la animadversión para el dictador Rosas, complementada en la acción como un fuerte opositor que, sin duda, contribuyó a derrotarlo.

En cuanto a la "Introducción" como texto integral, es notorio el recurso a un epígrafe en francés (cultura que él admira) que sustenta su posición como testigo de la historia de su país. La evocación a Facundo, en el inicio mismo, revela una forma literaria 
que sugiere a un narrador que conoce muy bien a los personajes de la intrincada y apasionada historia épica argentina.

Con el recurso argumentativo de las oposiciones binarias. Sarmiento desarrolla todo un tratado sobre lo que debe y no debe hacerse en América: culto/salvaje, urbe/pampa, Europa/España, Europa no española/ América, América Sajona/Latinoamérica, seres degradados/almas generosas, federalistas/unionistas, Europa mundo civilizando cristiano/América mundo civilizable.

Aunque Sarmiento hable de un retorno a las raíces nacionales y a lo popular (párrafo 2), cae en contradicción cuando señala a los europeos no españoles como los llamados a despertar a los argentinos de su letargo. Esto puede ser atribuido a la premura con que Sarmiento escribió el Facundo, en la exasperación del exilio, no obstante la buena acogida que tuvo en Chile; y también al acopio de temas que forman esta "introducción", donde además destacan el determinismo y positivismo característicos del autor en relación con algunos aspectos de la identidad latinoamericana.

\section{Nuestra América de José Martí}

Inicia Martí su ensayo con una idea propia de lo que posteriormente se definiría como elementos del pensamiento martiano: la solidaridad y fraternidad entre pueblos homólogos. Cuando habla de aldeano vanidoso reducido al mundo de su aldea, utiliza un contenido negativo que refuerza la idea positiva que esgrime al final del mismo párrafo: "trincheras de ideas valen más que trincheras de piedras". Este primer párrafo es de por sí una pieza literaria, dentro de una línea ensayística en la cual también han descollado otros autores latinoamericanos con antecedentes poéticos; prevalece un lenguaje exquisito pleno de figuras literarias, tales como:

- aliteraciones:

"el aldeano vanidoso que e] mundo entero es su aldea y con tal que él quede de alcalde".

- antítesis:

"trincheras de ideas... trincheras de piedras"

- comparación:

"las armas de almohada... como los varones de Juan de Castellanos".

- inversión:

"cree el aldeano vanidoso"

"crezcan en la alcancía los ahorros"

- metáfora:

"acostarse con las armas de almohada"

"llevan siete leguas en las botas"

- prosopopeya:

"la pelea de los cometas en el cielo"

"aldea... ha de despertar"

"los cometas... engullendo mundos"

"el aire dormido"

- si' repetición:

"o le mortifiquen... o le crezcan",

"trincheras de ideas... trincheras de piedras"

"siete leguas en las botas... poner la bota encima"

- sinécdoque

(de sentido literal a sentido figurado):

"los cometas en el cielo... [los cometas] engullendo mundos"

"trincheras de piedras... trincheras de ideas" 
- sentencia:

"Trincheras de ideas valen más que trincheras de piedras"

"las armas del juicio... vencen a las otras".

La abundancia de figuras retóricas en el primer párrafo es apenas una muestra de lo que prevalece en todo el texto. Sin duda, este recurso estilístico tiene un efecto especial en el lector, por la fascinación que puede despertar en él, con lo que la función didáctica propia del género ensayístico se cumple a plenitud. El tratamiento dado a este párrafo puede aplicarse al resto de la obra con los mismos resultados, ya que en este texto martiano se da una homologación entre la forma literaria y el profundo contenido de sus ideas, con una clara intención de enseñar por medio de ejemplos cómo es la realidad latinoamericana en sus tres momentos: el pasado, el presente y el futuro; es decir, los errores pretéritos, la situación actual de alerta contra las amenazas internas y externas (lo endógeno y lo exógeno a la vez) y el porvenir que él prevé.

Martí es incisivo al hablar de los males de Nuestra América señalando a los culpables autóctonos y foráneos; pero a la vez, es justo reconocer lo bueno de afuera a la par de lo propio. No se trata sólo de eliminar lo criollo en beneficio de lo mestizo, sino de repudiar el criollismo exótico y reconocer el mestizaje autóctono.

Preocupado siempre por la identidad americana, el texto de Martí hace un llamado a quitarse la máscara, ese "ropaje extranjero" angloamericano y europeizante que no resolvía el problema hispanoamericano; sólo Hispanoamérica podrá hacerlo, con sus propios hijos creando, siendo auténticos para así dar origen al hombre nuevo. En esta tesitura va planteándose la propuesta de José Martí, con un intenso afán didáctico y persuasivo (llama, exhorta), con claro fundamento ideológico, algo ecléctica e idealista, con valor estético literario (literaturidad) y recursos retóricos que acercan el texto a la función poética.

En el planteamiento de las ideas que sustentan este ensayo, se sigue un orden lógico de lo menor a lo mayor: el aldeano, el sietemesino, el soberbio, el hombre natural y el hombre naciente como tipos representativos de la americanidad; luego, es América como la totalidad, como instancia integradora de todos esos individuos o tipos que la representan, hasta llegar al final a la idea de una América nueva en la que cifra su esperanza de salvación (lo profético en Martí).

También están presentes rasgos de universalidad, como su repudio al odio radical y su afirmación de que el alma es igual en todos. En un orden de ideas, pasa de lo particular a lo general: aldeano-Américael mundo, matizando los cambios y transiciones con imágenes que refuerzan los contenidos y enriquecen la forma.

"Nuestra América" es un valioso ejemplo de la forma ensayística, y a la vez un prototipo del ensayo latinoamericano, nacido en la forja de una identidad propia, con fuerte arraigo en la tierra americana y búsqueda de un destino común, que también es muestra fehaciente de su conocimiento del pueblo americano y de los hombres (lo universal). 


\section{IV: Ariel de J. E. Rodó}

El uruguayo José Enrique Rodó (18711917) escribe una obra hoy considerada clásica en el desarrollo del pensamiento latinoamericano: Ariel (1900), editada como parte de unan colección de opúsculos que él llama "La vida nueva".

A Rodó se le ubica dentro de la corriente modernista junto a Darío, Lugones y Herrera y Reissig, y es considerado un gran ensayista, muy influyente en su época gracias a su polifacética actividad como filósofo, periodista, político, educador y guía de juventudes. Su adscripción al modernismo la confiesa en el prólogo de las Prosas profanas de Darío:

- Yo soy un modernista también; yo pertenezco con toda mi alma a la gran reacción que da carácter y sentido a la evolución del pensamiento en las postrimerías de este siglo...

Con esta posición radical de cambio y renovación, el libro Ariel presenta una gama de personajes que ponen en la acción la utopía de un idealismo de cambio de siglo para la juventud de América, la cual es la esperanza futura del continente:

- Próspero, el maestro, es el idealista que representa la sabiduría;

- Ariel simboliza la libre voluntad, la creatividad, el sentido de la belleza, el ser ideal;

- Calibán corresponde al materialismo y al utilitarismo, componentes negativos que tratan de destruir lo esencial del individuo.
Podemos inferir varias ideas fundamentales como ejes temáticos:

- exaltación de la juventud, la libertad, el desarrollo de sí mismo, la verdad y conocimiento;

- reacción contra el positivismo, el utilitarismo y el materialismo como fuerzas destructivas;

- fortalecimiento de una especie de aristocracia intelectual como medio de resistir la infuencia de Calibán (Estados Unidos);

- visión profética sobre el porvenir brillante de América (responsabilidad que atañe a los jóvenes).

No obstante que Rodó condena el materialismo utilitarista sajón, elogia los aspectos que considera buenos de los Estados Unidos, como la educación pública, el trabajo, la libertad y el individualismo (como libertad individual). Con esta posición promueve la complementariedad de las dos Américas, la latina y la sojona, para marchar unidas. Así. también busca despertar la consciencia de Latinoamérica hacia la grandeza de su destino, es decir, de un territorio llamado a ocupar un lugar de privilegio en el desarrollo de la humanidad dado su potencial; esta es su visión optimista.

El mundo que el maestro Próspero presenta a sus discípulos ya no es una ilusión, a la manera de La vida es sueño, ya que América vive un momento trascendental: optar por un mundo materializado, o bien por una realidad más elevada; el mundo del progreso técnico que predican desde los Estados Unidos (materialismo burdo), o las facultades sutiles y universales de que disponen los 
latinoamericanos. El progreso visto como desarrollo técnico sólo lleva a la masificación; en cambio, la fortaleza del latinoamericano reside en el dominio individual, en la imposición de lo humano $\mathrm{y}$, contrario a la masificación, debe llegar a formar élites con una orientación independiente y soberana, a diferencia de la masa que se deja guiar por el pragmatismo inmediatista.

En el momento crucial de la aparición de Ariel, la obra cala hondo por su mensaje, su llamado de urgencia y su advertencia sobre la amenaza común contra Latinoamérica y España. La política de los Estados Unidos y su estilo particular de imponerse estaba produciendo una comunidad de espíritus entre españoles y latinoamericanos que comenzaban a sentir el poder amenazante de una cultura centrada en lo material y utilitario (Calibán).

El sentido de idealismo y utopía americana, de visionario y profeta, de maestro y modelo que nos muestra Rodó es comparable a Bolívar en su Carta de Jamaica y a Martí en Nuestra América. Rodó, ensayista puro, hace con este género literario una escuela de pensamiento que aporta enormemente a la identidad de América Latina, por lo que hoy día vale revisar lo esencial de su ideario.

\section{Siete ensayos de interpretación de la realidad peruana de José Carlos Mariategui}

Este conjunto de ensayos, publicados en 1928, reúne ideas e inquietudes ya planteadas por el autor en su revista Ámauta. Como el mismo título indica, Mariátegui utiliza el género ensayístico para interpretar (lo subjetivo) la realidad de su país a partir de opiniones propias y con la clara intencionalidad de contribuir a la construcción del socialismo en Perú (su utopía). Bien lo advierte en su prólogo: “... no soy un crítico imparcial y objetivo. Mis juicios se nutren de mis ideales, de mis sentimientos, de mis pasiones". En esta tesitura hay que entender lo que expone el ensayista y pensador político, quien vivió entre 1894 y 1930.

Los Siete ensayos conforman en sí mismos una unidad que encuentra su eje central en el tema de la preocupación por el porvenir de Perú, acorde con una visión optimista de un futuro más halagüeño para la gran nación latinoamericana, lo cual exigía a su vez amplio conocimiento de las realidades pasada y presente, nacional y continental, así como mucho control de lo subjetivo para lograr un desarrollo adecuado de la forma escrita. En esta visión personal, se mezclaban conocimientos consolidados a base de estudio, experiencias conformadas a partir de vivencias cotidianas y sufrimiento (la heroicidad de Mariátegui), a la vez que sentimientos sustentados en una educación y amor por la patria.

Es claro que Mariátegui -el Amauta-al analizar el mundo, el escenario de su país, se ve influido por una fuerte preocupación: dejar de lado el racionalismo científico, recrear el marxismo revolucionario y elaborar una postura que le permita integrar las motivaciones humanas que forman parte de la transformación social.

Los siete textos que se reúnen en este libro abarcan aspectos de la economía, del problema indígena, de la educación, de 
la religión, del regionalismo y de la literatura. Sin dejar de lado la interrelación temática, el segundo y el tercero están biunívocamente relacionados, por lo que nos centraremos en la problemática del indio como punto de interés.

Comenzamos por señalar que Mariátegui, desde sus ensayos en Temas de Nuestra América, había establecido diferencias conceptuales entre los términos: América indo-española, iberoamericanismo y panamericanismo. Sobre todo marca la oposición entre los dos últimos y destaca el valor del primero como sustento de la hermandad de los pueblos en la unidad del pasado, presente y futuro. También, el nombre Amauta que le da a su revista, en 1926. traduce su adhesión a la raza, al incaísmo. En la revista colaboraban intelectuales preocupados por el problema indígena y por encontrarle una salida, es decir, no quitarle al indio su utopía de vivir tiempos mejores (justicia social, dignidad).

La problemática del indio en Perú tiene su origen en la transformación social que sufrió el territorio a partir de la conquista española hasta la actualidad. Lo que pudo ser una convivencia armoniosa en virtud del encuentro de dos culturas diferenciadas, se convirtió en una alteración de los planos donde lo hispánico (españoles, criollos, blancos) se impuso a lo indígena, cuyos vestigios más representativos del pasado son los pueblos de habla quechua y aymara. En este proceso, lo más impactante fue la pérdida de la tierra, o sea, el desposeimiento del espacio natural para convertirse en trabajadores sin paga (esclavos) de los blancos, lo que Mariátegui asocia con el gamonalismo. Este fenómeno se basa en la figura del gamonal o señor feudal que ejerce su autoridad sobre sus súbditos (indígenas, campesinos) y su poderío se extiende a las demás esferas de la sociedad (gobierno, parlamento, etc.) en su beneficio. A este respecto, son bien conocidas las rebeliones de indios contra el estado de cosas que los avasalla, pero la solución no llegaba.

No hay que dejar de lado que el problema del indígena es el problema del campesinado, porque esta población es esencialmente de tal ascendencia, lo que refuerza a Mariátegui en su afirmación de que el problema es de origen económico y está implícitamente relacionado con la tierra. Otras explicaciones acerca del origen de esta problemática no pueden, por ende, ser aceptadas: tales como lo étnico que tradicionalmente ha impulsado el imperialismo europeo. Además, remitir el problema a otros ámbitos (administrativo, moral, educativo, por ejemplo), no es sino caer en un reduccionismo que coarta las vías de solución y crea intentos fallidos -aunque bien intencionados-de lograr una justa salida. De allí que el derecho a la tierra, que es su tierra de por sí, viene de primero; después vendrán los otros derechos, como la educación.

El planteamiento de Mariátegui, focalizado en el asunto de la tierra, debe ser el producto de su conocimiento del pasado ancestral, desde la época prehispánica, pasando por la conquista, la colonia y el período republicano. Dentro de este contexto de siglos de desarraigo, la posición del ensayista adquiere mayor sentido y proporción. La utopía, pues, consistiría en la recuperación de la tierra y construirse un mundo mejor, no como una vuelta a 
lo pasado (arcaísmo), sino como la edificación del futuro sobre sólidas bases de justicia, dignidad, igualdad e identidad. Se trata del encuentro con el pasado en lo que a derechos naturales se refiere, y la reinvindicación del presente en lo que concierne a la convivencia con otros sectores coexistentes. Esto es parte del pensamiento de Mariátegui en su etapa de madurez, cuando él habla de poner toda su sangre en sus ideas, a la manera de Nietzsche.

\section{Bibliografía}

Mariátegui, José Carlos. 7 ensayos de interpretación de la realidad peruana. Lima: Editorial Amauta, 1964.

Martí. José. Nuestra América. Buenos Aires: Losada, 1980.

Meléndez, Carlos (comp.). Textos fundamentales de Bolivar. Heredia: ELTNA, 1983.

Rodó, José Enrique. Ariel. $3^{\mathrm{a}}$ ed. Buenos Aires: Kapelusz, 1980.

Sarmiento, Domingo F. Facundo. $3^{\mathrm{a}}$ ed. Buenos Aires: Losada. 1969. 